\title{
Fuzzy-Sliding Mode Speed Control of Permanent Magnet Synchronous Motor Using NPC Converter
}

\author{
Naoufl Ettalabi ${ }^{1}$, Mostafa Bouzi ${ }^{1}$, Badre Bossoufi ${ }^{2}$, Kamal Anoune ${ }^{3, *}$ and Elmarghichi Mouncef ${ }^{1}$ \\ ${ }^{1}$ Laboratory of Mechanical, Computer science Electronics, and Telecommunications \\ Faculty of Sciences and Technologies of Settat, Hassan First University, Morocco. \\ ${ }^{2}$ LIMAS Laboratory, Faculty of Sciences Dhar El Mahraz, Sidi Mohamed Ben Abdellah University, Fez, Morocco. \\ ${ }^{3}$ Laboratory of Informatics, Systems \& Telecommunications, Faculty of Sciences and Technologies of Tangier-Abdelmalek- \\ Essaadi University (UAE), Ziaten. BP: 416, Tangier, Morocco.
}

*ORCID: 0000-0002-6418-4051

\begin{abstract}
These days, the researches on permanent magnetic synchronous motors (PMSMs) as mechanical power sources have obtained more and more attention. the popular strategies applied to control the machine speed presents higher standards for torque response speed and accuracy of the PMSMs control system. To follow the reference motor speed as quick as possible, a sliding mode (SM) motor speed controller that can decouple q-axis and d-axis currents is proposed Moreover, To mitigate the well-known chattering phenomenon caused by the discontinuous term in a steady state of the conventional sliding mode control, a Fuzzy logic algorithm is introduced. The proposed Fuzzy-SMC performance is tested in simulation using MATLAB/Simulink environment. To eliminate the chattering phenomenon a combination of the command in sliding mode and the fuzzy logic is adopted. The proposed method also can guarantee the robust control of PMSMs under model parameters (resistance, inductance) and load torque variations. Based on the obtained results, it is clear that a fuzzy sliding mode controller can perform better than the conventional PI controller in terms of rising time, overshoot, settling time, and steady-state error. The effectiveness of the combined Fuzzy-SM Controller also can guarantee the robust control of PMSMs and shows that this command did not depend on machine parameters (resistance, inductance) comparing to other existing commands and the chattering effect is reduced using this proposed method.
\end{abstract}

Keywords: PMSM, Sliding Mode Control, Fuzzy logic, Speed control, NPC.

\section{INTRODUCTION}

The development of digital calculators such as DSP and FPGA improves the numerical PMSM control drives. These modern platforms allow developing nonlinear controls that improve the performance of the systems with different noise and uncertainties i.e., robust control [1], direct torque control[2], intelligent control[3], ..., adaptive control[4] and sliding mode control (SMC)[5]. This last method is applied in many control fields [6][7].

The main drawback of the conventional PI is the sensitivity to parameter uncertainty and variation. In Many Applications, the SMC is attractive and recommended compared to conventional PI. In [8] a sliding mode control is used to ensure a high-accuracy positioning of a six-phase induction machine in both healthy and faulted modes. The research work of Lin. C [9] proposed an adaptive non-singular terminal sliding mode tracking control is designed to provide faster convergence and higher precision control for robotic systems. Besides, the SMC can be combined with other approaches to ensure the stability of system control [10].

However, the SMC suffers from well-known drawbacks such as the chattering phenomenon induced at a steady state due to the discontinuous term in the control law. Moreover, once used associated with conventional vector control to control the speed of PMSM, it leads to vibration. Subsequently, the torque ripple and power losses increase considerably. Various methods have been proposed to overcome the charting problems, such as complementary sliding-mode method[11], reaching law method [12],[13], and high-order sliding-mode method [14],[15]. By making the discontinuous gain a function of the sliding-mode surface, the chattering are reduced in [13]. Sliding Mode Control is assumed to construct the speed and current integrated controller in[16], using a novel Exponential Law. In the research work of Murat Karabacak et al.[17], they proposed a modelling, design, and simulation a tacking control approach based on adaptive backstepping speed tracking control to solve an uncertain occurred in permanent magnet synchronous motor PMSM, their numerical result confirms that strong robustness can be generated by the proposed controller to solve all uncertainties parameter. Jinpeng Yu et al. [18] developed an adaptive fuzzy tracking to control based backstepping to control the chaotic PMSM drive system, they compare the conventionnel backstepping technique with an adaptative backstepping technique, as a result, the developed adaptative technique can delete the chaos of PMSM drive systems and also track successfully the reference signal. A comparative study conducted by the research team of Bouzeria $H$ et al. [19] where the fuzzy logic technics are used to control the PMSM speed for a water pumping application, PMSM has to works in its maximum efficiency whatever the weather condition, they have compared and analyzed the performance between controllers based fuzzy logic and controllers based proportional integrator according to the speed and load 
variation test. B. Adhavan et al. [20] Presented a fuzzy logic approach to control the PMSM by applying space vector modulation, a comparative study between the conventionnel PI controller and the design Fuzzy logic controller proves that the fuzzy logic controller presents a good performance. Dandan et al. [21] focused to develop a controller-based sliding mode capable to control the torque of a permanent magnet synchronous motor (PMSMs) for an electric vehicle, this allows to delete the chattering phenomenon by adopting exponential reaching law, as result, robust control of PMSM is reached under model parameter and variation torque.

In these works, the main idea is to smooth the control action across the sliding surface. For this, the PI speed controller is replaced by an SM controller to make the control of PMSM presents no dependency in terms of parameter variation. However, a Fuzzy logic algorithm is introduced to adjust the weight of the SM gain, in such a way, it can be taken large than the standard value during the transient period to conserve the SMC performance and reduce the chattering effect in steady-state.

\section{PERMANENT MAGNET SYNCHRONOUS MOTOR MODEL}

Voltage and flux equations of permanent magnet synchronous motor expressed in the $\mathrm{d}-\mathrm{q}$ reference frame are given by [10]:

$v_{d}=R_{s} i_{d}+\frac{d \varphi_{d}}{d t}-\omega \varphi_{q}$

$v_{q}=R_{s} i_{q}+\frac{d \varphi_{q}}{d t}+\omega \varphi_{d}$

$\varphi_{d}=L_{d} i_{d}+\varphi_{f}$

$\varphi_{q}=L_{q} i_{q}$

Since the electromagnetic torque is described by:

$T_{e}=\frac{3}{2} p\left[\varphi_{f} i_{q}+\left(L_{d}-L_{q}\right) i_{d} i_{q}\right]$

Besides, the second law of Newton allows to deduce the following mechanical equation:

$J \frac{d \omega_{r}}{d t}=T_{e}-B \omega_{r}-T_{L}$

Where:

$v_{d}, v_{q} \mathrm{~d}$ and $\mathrm{q}$ axis stator voltages.

$i_{d}, i_{q} \quad \mathrm{~d}$ and $\mathrm{q}$ axis stator currents.

$\varphi_{d}, \varphi_{q} \mathrm{~d}$ and $\mathrm{q}$ axis stator flux.

$L_{d}, L_{q} \mathrm{~d}$ and $\mathrm{q}$ axis stator inductances.

$T_{e}, T_{L}$ electromagnetic and load torque.

$R_{s}$ stator resistance.

$\varphi_{f}$ flux linkage created by rotor magnets.
$J$ moment of inertia.

$B$ coefficient of viscosity.

$p$ number of poles pairs.

$\omega$ electrical frequency.

$\omega_{r}$ rotor speed.

Angular frequencies are related as a function of the number of pair pole:

$\omega=p \omega_{r}$

Hence, the state equation of permanent magnet synchronous motor is deduced as follow:

$$
\left\{\begin{array}{l}
\frac{d i_{d}}{d t}=-\frac{R_{s}}{L_{d}} i_{d}+\frac{p L_{q}}{L_{d}} \omega_{r} i_{q}+\frac{1}{L_{d}} v_{d} \\
\frac{d i_{q}}{d t}=-\frac{R_{s}}{L_{q}} i_{q}-\frac{p L_{d}}{L_{q}} \omega_{r} i_{d}-\frac{p \varphi_{f}}{L_{q}} \omega_{r}+\frac{1}{L_{q}} v_{q} \\
\frac{d \omega_{r}}{d t}=\frac{3 p}{2 J}\left[\varphi_{f} i_{q}+\left(L_{d}-L_{q}\right) i_{d} i_{q}\right]-\frac{B}{J} \omega_{r}-\frac{T_{L}}{J}
\end{array}\right.
$$

\section{NEUTRAL POINT CLAMPED CONVERTER (NPC)}

\subsection{Configuration of NPC converter}

Neutral Point Clamped (NPC) inverters, which are diodes connected to the midpoints of the voltage sources, protecting the external switches against excessive voltages. This topology requires rigorous control of the voltages of each capacitor and the balancing of the voltages becomes complex beyond three levels. Also, the number of diodes increases very rapidly with the number of levels.

The structure of the neutral point clamped converter is sketched in Figure. 1. The continuous side is divided into two equal voltages using two capacitors.

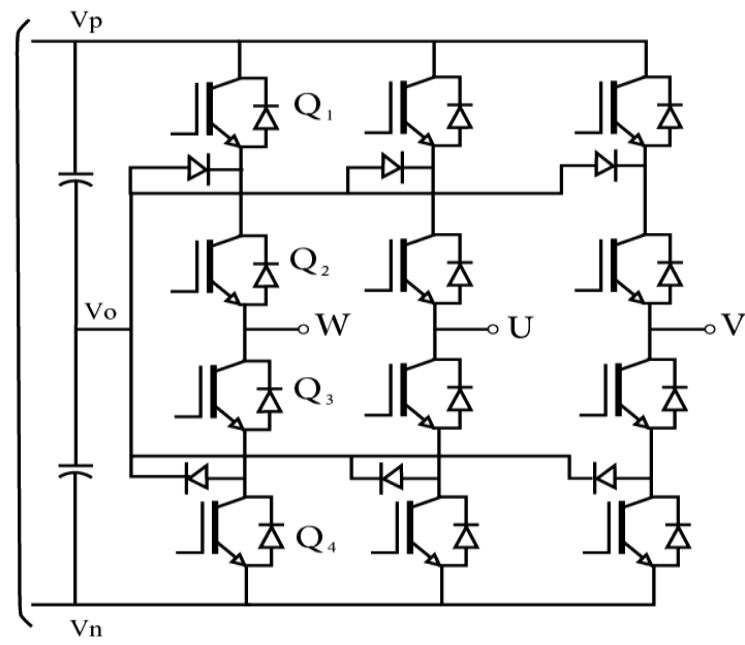

Figure. 1: Configuration of NPC converter.

Each leg is composed of four IGBTs connected in series. Each leg is expected to be completed by two clamp diodes. For one 
phase, when IGBT Q1 and Q2 are turned on, the output is connected to $V_{p}$; when $\mathrm{Q} 2$ and $\mathrm{Q} 3$ are on, the output is connected to Vo; and when Q3 and Q4 are on, the output is connected to $\mathrm{Vn}$. The switching states of the IGBTs are listed in Table 1.

Table 1. Switching states

\begin{tabular}{|c|c|c|c|}
\hline IGBT & Vout=Vp & Vout=Vo & Vout=Vn \\
\hline Q1 & On & Off & Off \\
\hline Q2 & On & On & Off \\
\hline Q3 & Off & On & On \\
\hline Q4 & Off & Off & On \\
\hline
\end{tabular}

\subsection{Sinusoidal Modulation using Multiple Carrier Waves (SPWM)}

The multilevel SPWM modulation method is based on the comparison between the sinusoidal reference and many vertically shifted carrier signals.

For two levels, the scheme is illustrated in Figure. 2. During a PWM period, if the modulation wave is greater than the upper carrier wave, switch Q1 is on and Q3 is off. In contrast, if the modulation wave is greater than the lower carrier wave, switch Q2 is on and Q4 is off.
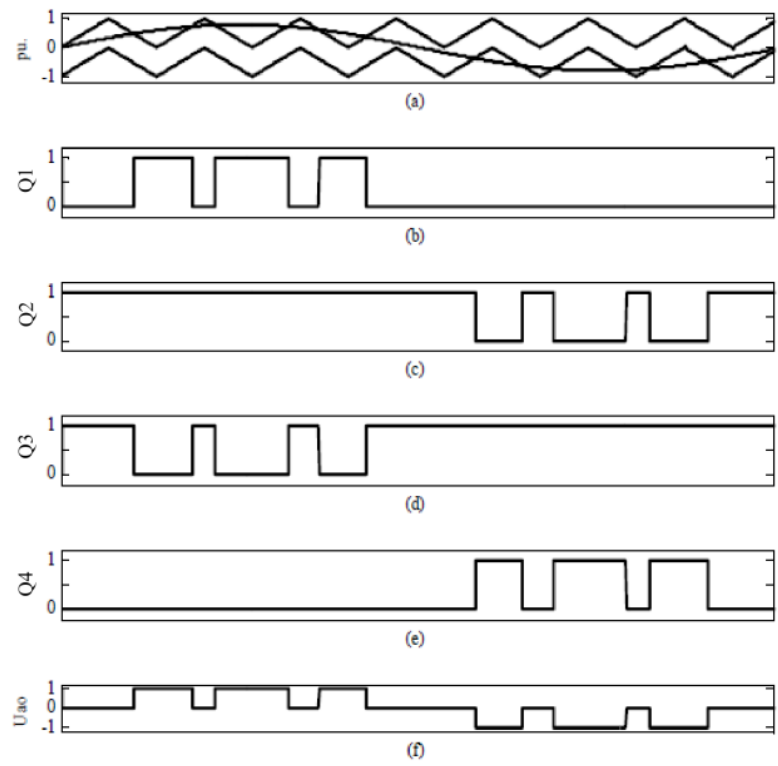

Figure. 2 (a) SPWM scheme for three-level NPC inverter, (b)-(e) the gate signals for switches $\mathrm{Sa} 1, \mathrm{Sa} 2, \mathrm{Sa} 3$, and $\mathrm{Sa} 4$, (f) output phase voltage

\section{SLIDING MODE CONTROLLER DESIGN}

Sliding Mode Control (SMC) has a proven history of its performance. It is considered as a nonlinear control method that presents good performance. It has been employed in several applications investigated in the literature [6][7] and has been applied to different systems with various behaviors. The implementation of sliding mode control is simple; it is based on state-space equations of the studied system and robust against external disturbances and process change.

Sliding Mode Control is known also as a Variable Structure Controller (VSC) since it is a discontinuous controller. In VSC, the idea is to bring the plant states to a user-defined surface called a sliding surface.

Sliding mode control is designed through three steps, which are:

\section{- Choice of the control surface}

Considering the nonlinear system defined by the following form:

$$
\dot{X}=g(X, t)+b(X, t) u(X, t)
$$

Where $X \in \mathfrak{R}^{n}, u \in \mathfrak{R}^{m}, g(X, t) \in \mathfrak{R}^{n}, b(X, t) \in \mathfrak{R}^{n \times m}$, $g(X, t)$ and $b(X, t)$ are two non-linear functions, continuous, and limited.

The sliding surface is given by:

$S(X)=\left(\frac{d}{d t}+\delta\right)^{n-1} e$

Where $e=X^{r e f}-X, X^{r e f}=\left[x^{r e f}, \dot{x}^{r e f}, \ddot{x}^{r e f}, \ldots\right]^{T}$,

$e$ is the error, $\delta$ is a positive constant, $X^{r e f}$ is the reference signal, and $X$ is the state variable.

\section{- Convergence condition}

Lyapunov function defines the convergence condition:

$$
S(X) \cdot \dot{S}(X) \leq 0
$$

\section{- Control calculation}

Usually, the basic control law of sliding mode control that can guarantee the asymptotic stability for such systems is given by:

$u=u^{e q}+u^{n}$

Where is the control signal is the equivalent control, and is the switching term which defined by the sign function of the sliding surface multiplied by a positive constant:

$u^{n}=-k \cdot \operatorname{sign}(S(X))$

Where $k$ is a positive constant, $S(X)$ is the switching function, and $\operatorname{sign}($.$) is the sign function.$

Let us apply this theory to control the speed of the PMSM. The sliding surface is defined is below:

$S\left(\omega_{r}\right)=\omega_{r}^{*}-\omega_{r}$

Calculating the derivative of the sliding surface, and neglecting of speed dynamics, yielding:

$\dot{S}\left(\omega_{r}\right)=-\frac{3 p \varphi_{f}}{2 J} i_{q}+\frac{B}{J} \omega_{r}+\frac{1}{J} T_{L}$ 
In this case, the control is the quadratic current, the control law is calculated as:

$i_{q}^{*}=\frac{2}{3 p \varphi_{f}}\left(B \omega_{r}+T_{L}^{*}-k \operatorname{sgn}\left(\mathrm{S}\left(\omega_{r}\right)\right)\right)$

Where the load torque was estimated from the speed and the PMSM quadratic control current iq based on the Eq. 8 at steady state as follows:

$T_{L}^{*}=\frac{3 p \varphi_{f}}{2} i_{q}-B \omega_{r}$

Now, for the direct current, the sliding surface is defined as:

$$
S\left(i_{d}\right)=i_{d}^{*}-i_{d}
$$

As one mentioned before the direct current should be controlled to zero. However, the derivative of the sliding surface becomes:

$$
\dot{S}\left(i_{d}\right)=R_{s} i_{d}-\frac{p L_{q}}{L_{d}} \omega_{r} i_{q}-\frac{1}{L_{d}} v_{d}
$$

Therefore, the control law is calculated as follows:

$$
v_{d}^{*}=R_{s} i_{d}-p L_{q} \omega_{r} i_{q}-k \operatorname{sign}\left(S\left(i_{d}\right)\right)
$$

It seems from Eq. (16) and Eq. (20), that the control law contains the discontinuous term which ensures the stability and the sliding control attraction. Nevertheless, it generates ripples depending on the value of $\mathrm{k}$. To mitigate this gain effect, a fuzzy logic method is proposed.

The sliding mode control scheme of the PMSM is outlined in Figure.3.

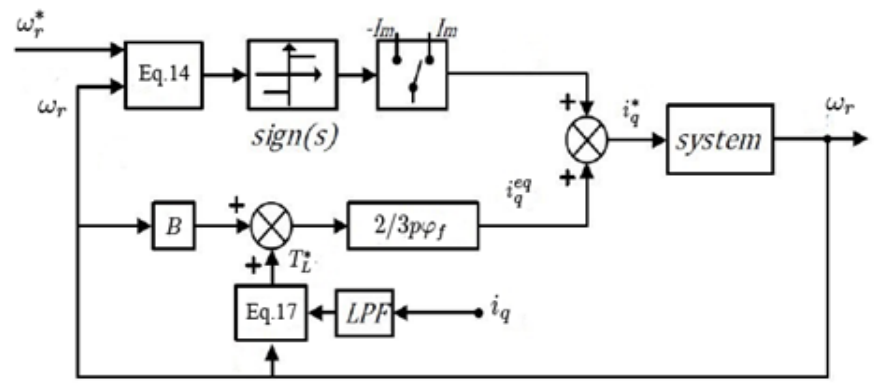

Figure 3. Sliding mode control of PMSM.

\section{CHATTERING MINIMIZATION USING FUZZY LOGIC}

To minimize the chattering phenomenon, a mitigation term is calculated using fuzzy logic. The principle is to multiply the discontinuous term of sliding mode with a mitigation term calculated using the Sugeno fuzzy inference technique. The fuzzy controller has two inputs; the sliding surface $S$ and the measured angular speed $\Omega$. The proposed scheme to control PMSM using the fuzzy sliding mode technique is illustrated in Figure.4.

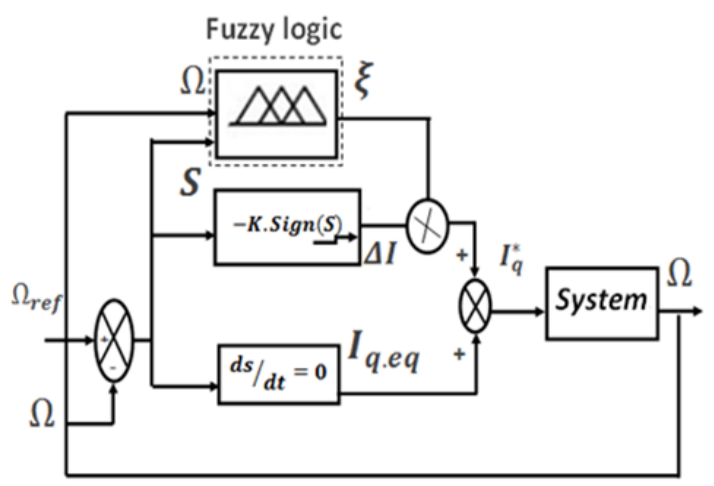

Figure 4. FSMC scheme.

Five fuzzy sets are used to describe the distance between the operating point and sliding surface, and three fuzzy sets are exploited to outline the speed range. Furthermore, three additional fuzzy sets are presented to define the appropriate mitigation value in the output of the fuzzy block as shown in Figure.5
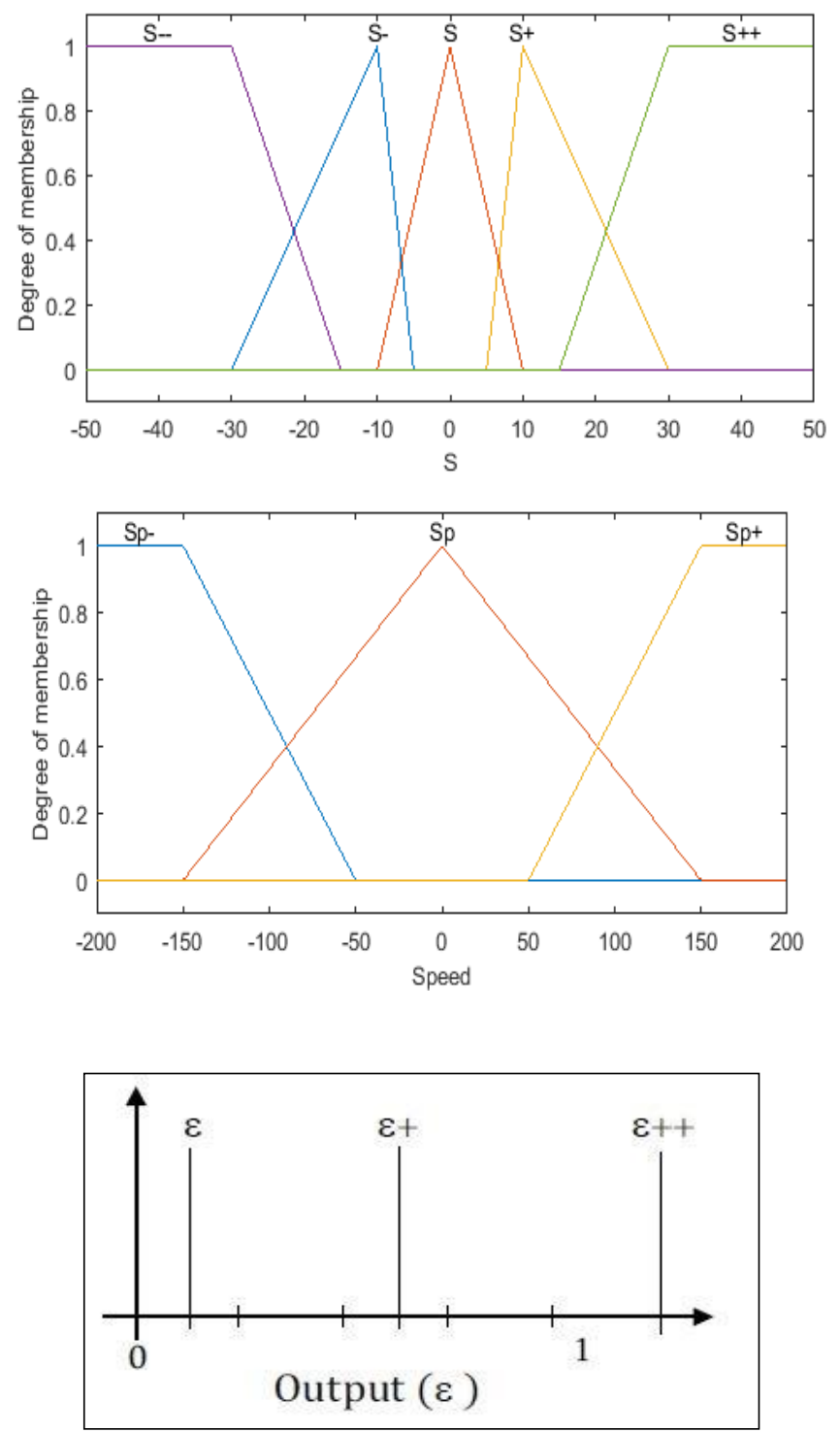

Figure.5. Inputs and outputs fuzzy sets 
However, the fuzzy inputs/outputs rules are arranged in table 2 .

Table 2. Rule base for fuzzy controller

\begin{tabular}{|c|c|c|c|c|c|}
\hline Input & S-- & S- & S & S+ & S++ \\
\hline $\boldsymbol{\Omega}-$ & e++ & e+ & e & e+ & e++ \\
\hline $\boldsymbol{\Omega}$ & e++ & e+ & e & e+ & e++ \\
\hline $\boldsymbol{\Omega}+$ & e++ & e+ & e & e+ & e++ \\
\hline
\end{tabular}

The resulting control surface of the proposed fuzzy controller is illustrated in Figure.6

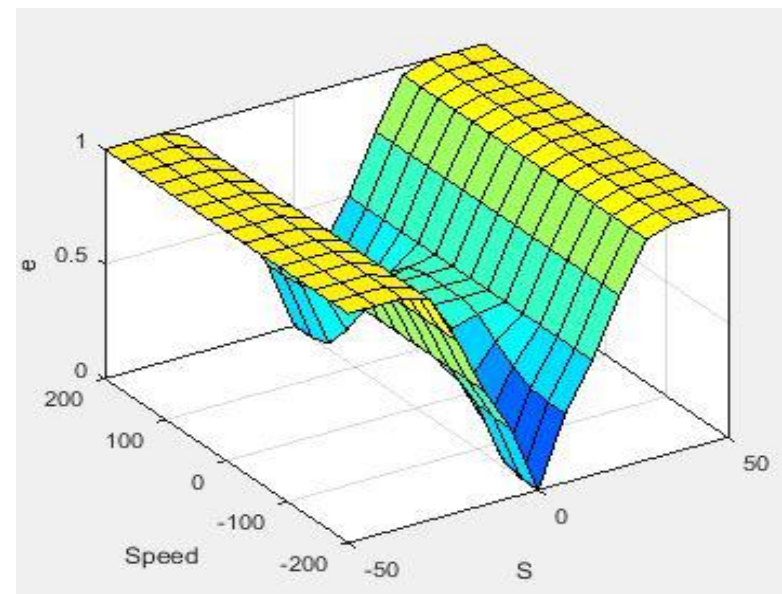

Figure 6. The control surface of the fuzzy controller

\section{SIMULATION RESULTS}

The Fuzzy Sliding Controller of the PMSM using the NPC converter is implemented in MATLAB/Simulink and the results are compared with the conventional sliding controller. The block diagram of the sliding mode control of PMSM with Fuzzy chattering minimization is shown in figure.10.

The simulation is conducted on a $3.6 \mathrm{KW}$ PMSM. It is then simulated by placing the conventional sliding controller first, then Fuzzy Sliding Controller in a second time.

A load torque of $15 \mathrm{Nm}$ is applied at the start. Figure. 7 shows the response of the system with conventional sliding mode control and fuzzy sliding mode control for a reference speed of $80 \mathrm{rad} / \mathrm{s}$. it is clear that the performance of the fuzzy sliding mode controller is better than that of the conventional sliding controller in terms of its peak overshoot and settling time. Nevertheless, chattering is unreduced sliding mode combined with fuzzy logic as illustrated in Figure.8.

For optimum operation at maximum electromagnetic torque, the solution is to keep the direct current ids (in the $\mathrm{d}$ axis) equal to zero and to regulate the motor speed by the transverse current $I_{q s}$ (in q axis) via the voltage $V_{q s}$ (in q axis) as shown in the diagram in Figure. 9.
The reduction of the current in the $\mathrm{d}$ axis makes it possible to reduce the losses by Joule effect, therefore the optimization of the efficiency in the stator of the synchronous permanent magnet machine.

Figures from (11) to (18) present the results of the simulation of control by sliding mode in combination with fuzzy logic with an increase in the value of the stator resistance $(+150 \%$ $\mathrm{RS}$ and $+200 \% \mathrm{RS})$ and an increase in the values of the inductances $L_{d}, L_{q}\left(+150 \%\left(L_{d}, L_{q}\right)\right.$ and $\left.+200 \%\left(L_{d}, L_{q}\right)\right)$.

The simulation's results show that the control by sliding mode and applied fuzzy logic is insensitive to parametric variations. Therefore, this command presents good robustness concerning the parametric variations.

Figure 7 illustrates a comparison of the synchronous machine speed response using the sliding mode controller and Fussy sliding mode controller, the Fuzzy sliding mode controller is better comparing to sling mode controller of which It provides a fast-dynamic response.

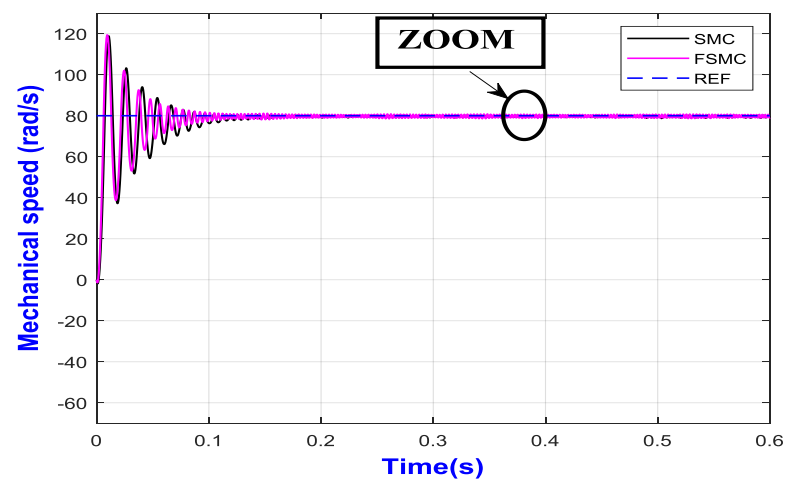

Figure. 7. The response of mechanical speed using a conventional fuzzy controller.

Figure 8 enlarges a range of mechanical speed response. This zoom is done between the instants $[0.375 \mathrm{~s} 0.4 \mathrm{~s}]$. it is deductible that the undulations of the Fuzzy sliding Mode Controller which are estimated to ' $0.6 \mathrm{rad} / \mathrm{s}$ ' are more reduced compared to the Sliding Mode Controller (a deviation of 1.8 $\mathrm{rad} / \mathrm{s})$.

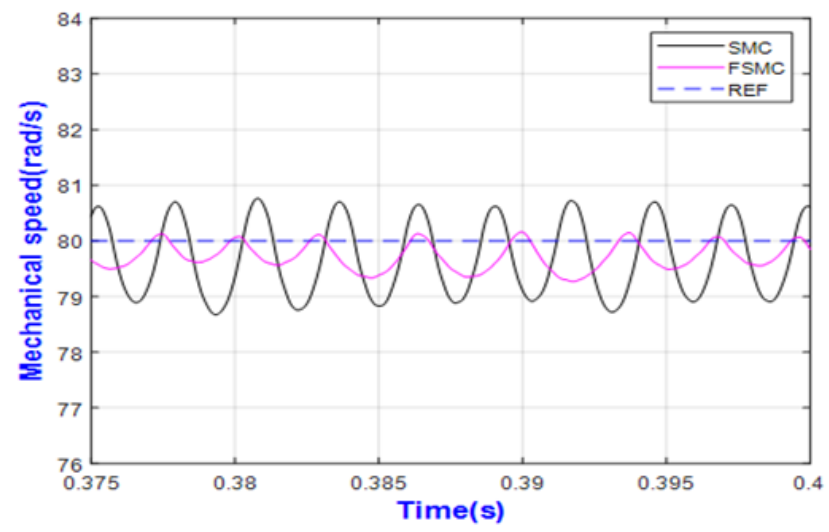

Figure 8. Zoom of the mechanical speed response. 


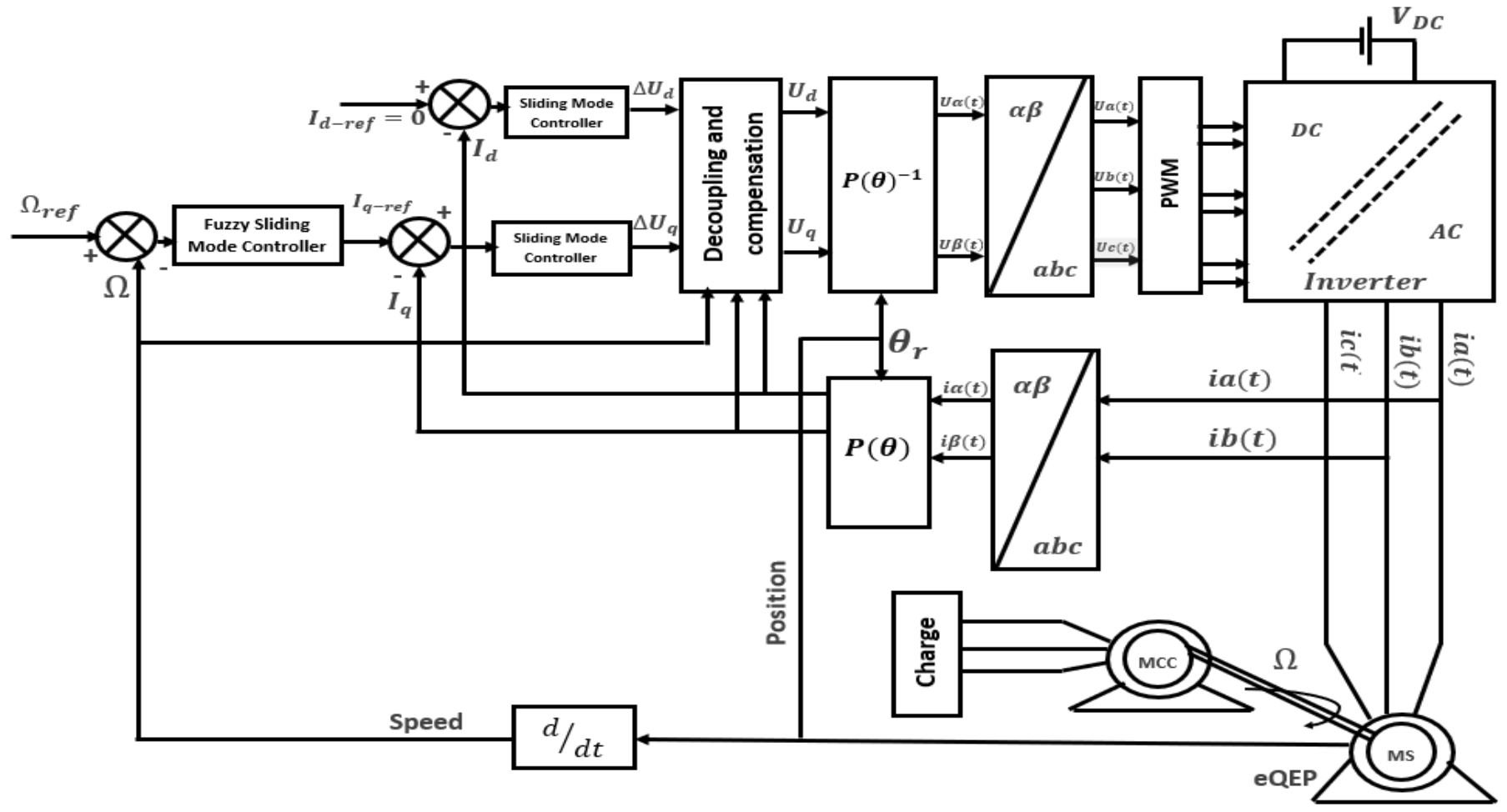

Figure. 10. Overall block diagram of the proposed control system.

Figure 9 illustrates the evolution of the currents in the axes $d$ and q. it can be noticed that the servo current $I_{d}$ is zero while $I_{q}$ tends towards $19 \mathrm{~A}$.

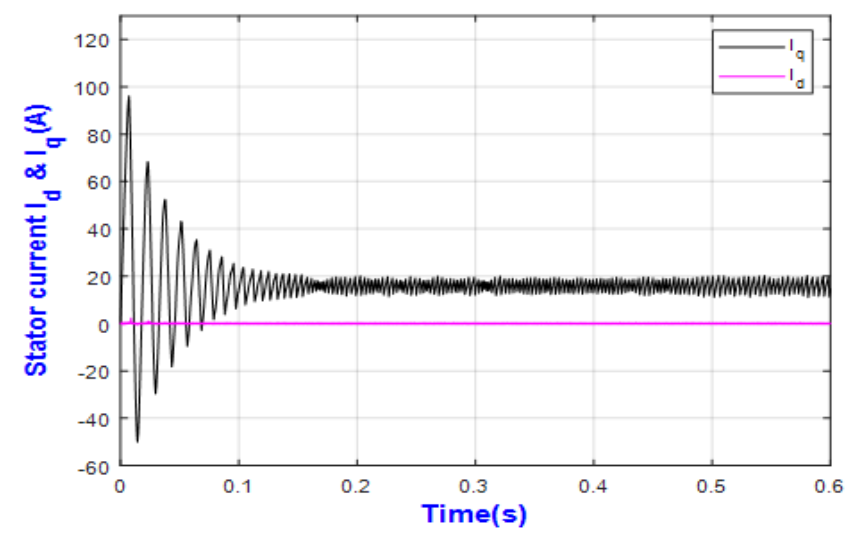

Figure 9. The response of stator current Id and Iq.

Figure 11 illustrates a performance comparison of the synchronous machine speed response using sliding mode controller and Fussy sliding mode controller by changing the values of machine parameters $\left(L_{d} \& L_{q}\right)$ as reference input.

An increase in these two parameters by $150 \%$ generated at the output two different responses, the FSMC response presents the best output performance.

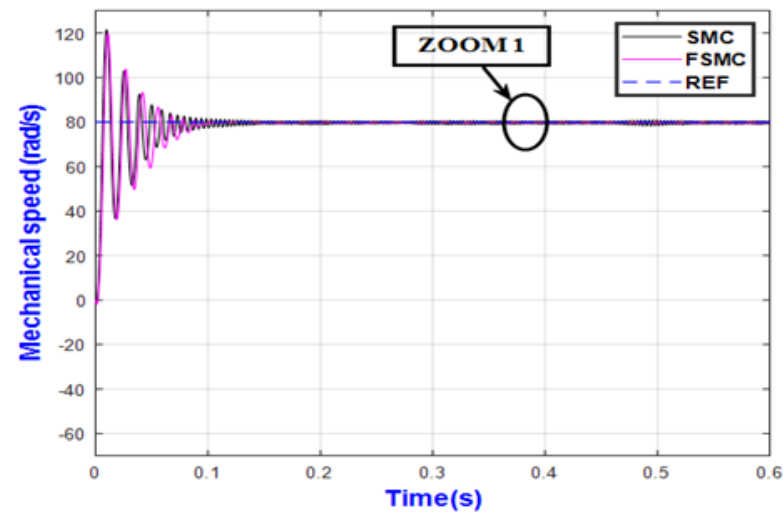

Figure 11. The response of mechanical speed using SMC on the FSMC Vs Reference signal.

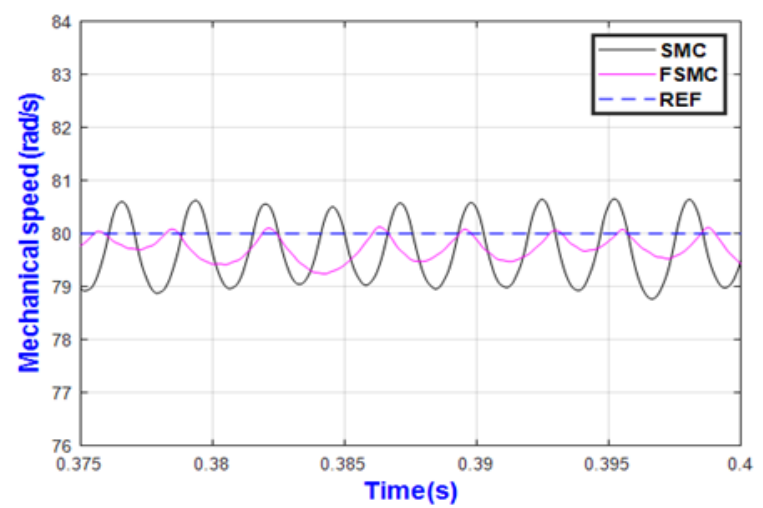

Figure 12. Zoom 1 of the response of mechanical speed using SMC on the FSMC Vs Reference signal. 
An enlargement range of the mechanical speed response (From the base on figure.11) is provided between the instants $[0.375 \mathrm{~s} 0.4 \mathrm{~s}]$. it appears that the undulations of the Fuzzy sliding Mode Controller are estimated as of $0.6 \mathrm{rad} / \mathrm{s}$ are more reduced comparing to the Sliding Mode Controller which consists of a gap of $1.4 \mathrm{rad} / \mathrm{s}$.

Figure .13 illustrates a comparison of the synchronous machine speed response using sliding mode controller and Fussy sliding mode controller by changing the values of machine parameters $\left(L_{d} \& L_{q}\right)$. An increase in these two parameters by $200 \%$.

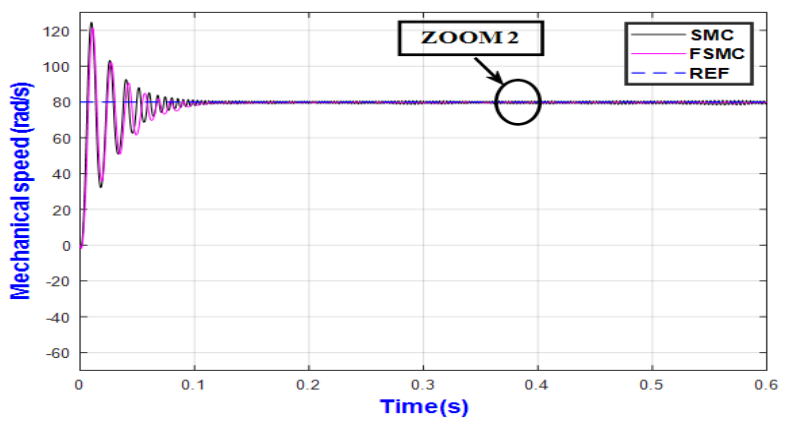

Figure 13. The response of mechanical speed using conventional on the fuzzy controller for a $200 \%$ increase in the $L_{d}$ and $L_{q}$ value.

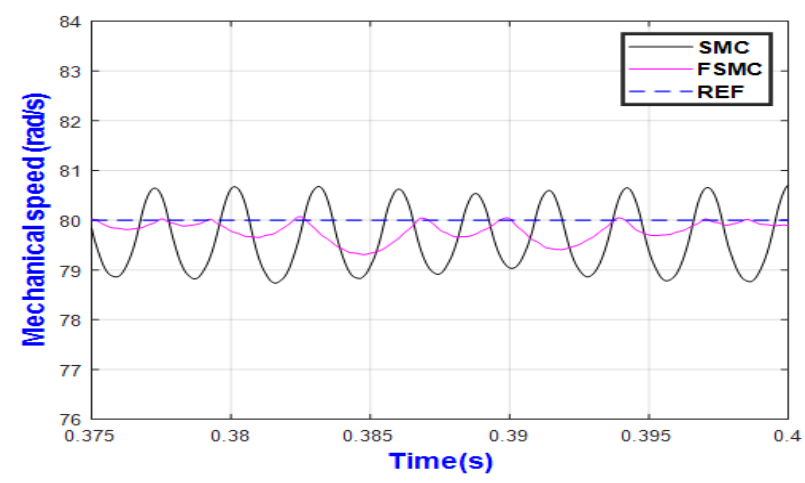

Figure 14. Zoom 2 of the mechanical speed using conventional on the fuzzy controller for a $200 \%$ increase in the $\mathrm{Ld}$ and $\mathrm{Lq}$ value.

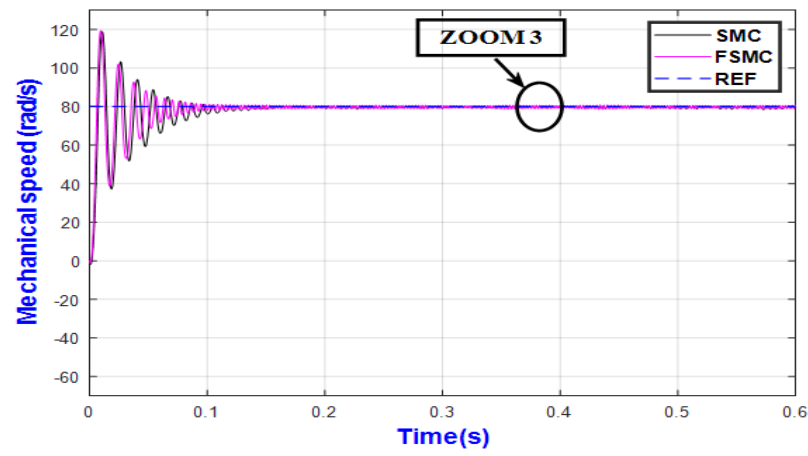

Figure 15. The response of mechanical speed using conventional on the fuzzy controller for a $150 \%$ increase in the Rs.

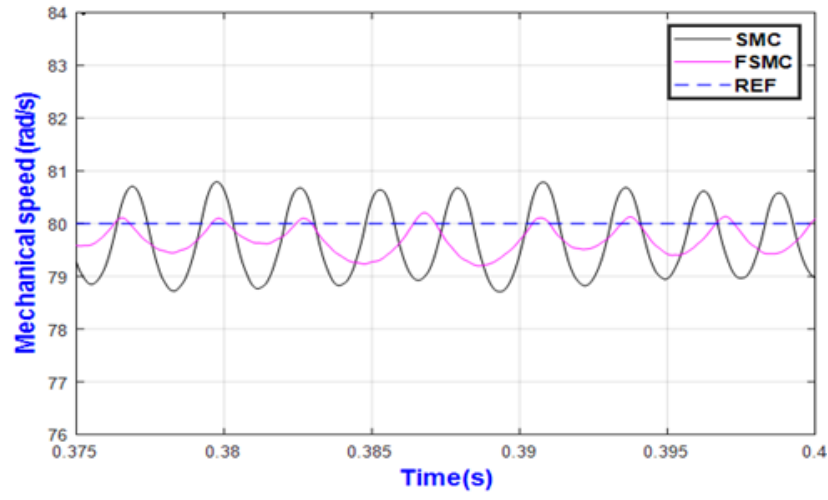

Figure 16. Zoom 3 of the mechanical speed using conventional on the fuzzy controller for a $150 \%$ increase in the Rs.

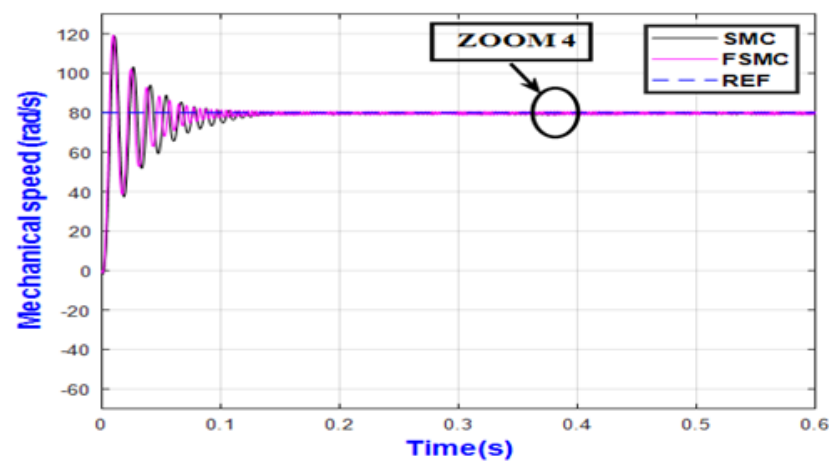

Figure 17. The response of mechanical speed using conventional on the fuzzy controller for a $200 \%$ increase in the Rs.

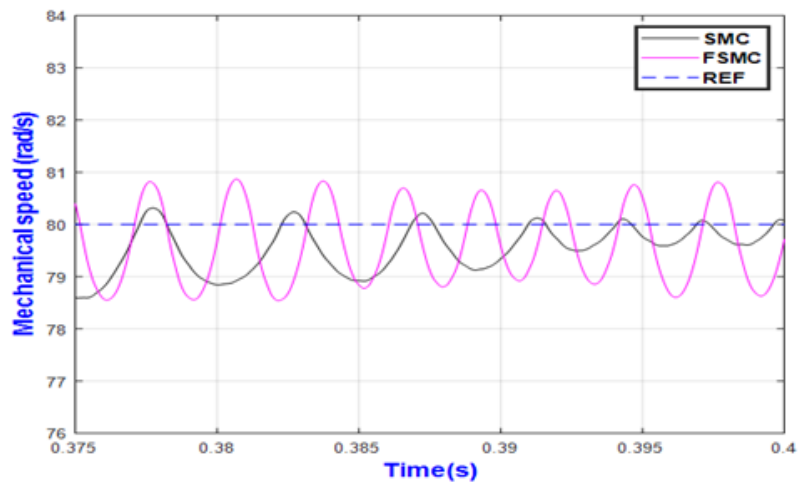

Figure 18. Zoom 4 of the mechanical speed using conventional on the fuzzy controller for a $200 \%$ increase in the Rs.

The figures13, 15 and 17 enlarge a range of the mechanical speed response using conventional on the fuzzy controller for s set-int point of a $200 \%$ increase related to the $L_{d}$ and $L_{q}$ value, an increase of $150 \%$ related to the Rs, and an increase of $200 \%$ related to the Rs. respectively. Their related illustration are tacked in the instant between [0.375s $0.4 \mathrm{~s}$, Zoom 2 in figure 14, provide an average undulation range of $\mathrm{FSMC}=0.6 \mathrm{rad} / \mathrm{s}$ and $\mathrm{SMC}=1.4 \mathrm{rad} / \mathrm{s}$, moreover, Zoom 3 in 
figure 16, provide an average undulation range of $\mathrm{FSMC}=0.7$ $\mathrm{rad} / \mathrm{s}$ and $\mathrm{SMC}=1.4 \mathrm{rad} / \mathrm{s}$, and finally, Zoom 3 in figure 18 , provide an average undulation range of $\mathrm{FSMC}=0.6 \mathrm{rad} / \mathrm{s}$ and $\mathrm{SMC}=1.4 \mathrm{rad} / \mathrm{s}$

\section{CONCLUSION}

Load variations and sensitivity to mechanical motor parameters are the important features required in PMSM speed control. Those advantages are ensured with the developed combination of the SM controller and the Fuzzy logic algorithm used to minimize the chattering phenomenon. First, an SM controller is designed using the electrical and mechanical PMSM equations, and the load torque is estimated using motor quadrature current and speed. Moreover, the SM discontinues term effects that manifest in current chattering and torque oscillation, are eliminated using a sliding mode associated with the fuzzy logic algorithm.

Simulation Results show good performances obtained with proposed control, with a good choice of parameters of control. The simulation results show Fast response and robust performance to parametric variation and disturbances in all the systems. The components $I_{d}$ and $I_{q}$ is regulated using the proposed control so that Id is zero

The Fuzzy Sliding Mode Controller combines the intelligence of fuzzy logic with the Sliding Mode technique. The effectiveness of this combination is validated through simulation test. Indeed, the chattering effect is reduced using fuzzy logic and the speed variation of the motor under loaded condition is reduced.

\section{APPENDIX}

PARAMETERS OF THESYNCHRONOUSMACHINE

\begin{tabular}{lc}
\hline \hline Designation & Value \\
\hline \hline Frequency & $50 \mathrm{~Hz}$ \\
Pole pairs (p) & 2 \\
Stator phase resistance $\left(R_{s}\right)$ & $1.35 \Omega$ \\
d axis inductance $\left({ }^{L_{d}}\right)$ & $7.66 \mathrm{mH}$ \\
q axis inductance $\left({ }^{L_{q}}\right)$ & $17 \mathrm{mH}$ \\
Permanent magnet flux $\left(\varphi_{f}\right)$ & $0.158 \mathrm{~Wb}$ \\
Moment of inertia $(\mathbf{J})$ & $0.0035 \mathrm{~kg} \cdot \mathrm{m}^{2}$ \\
Damping coefficient $(\mathbf{B})$ & $0.001 \mathrm{Nm} / \mathrm{rad} / \mathrm{s}$ \\
\hline \hline
\end{tabular}

\section{REFERENCES}

[1] Z. Ma and X. Zhang, "FPGA Implementation of Sensorless Sliding Mode Observer With a Novel Rotation Direction Detection for PMSM Drives," IEEE Access, vol. 6, pp. 55528-55536, 2018, doi: 10.1109/ACCESS.2018.2871730.

[2] G. H. B. Foo and M. F. Rahman, "Direct Torque Control of an IPM-Synchronous Motor Drive at Very Low Speed Using a Sliding-Mode Stator Flux Observer," IEEE Trans. Power Electron., vol. 25, no. 4, pp. 933-942, Apr. 2010, doi: 10.1109/TPEL.2009.2036354.

[3] C. B. Butt and M. A. Rahman, "Intelligent Speed Control of Interior Permanent Magnet Motor Drives Using a Single Untrained Artificial Neuron," IEEE Trans. Ind. Appl., vol. 49, no. 4, pp. 1836-1843, Jul. 2013, doi: 10.1109/TIA.2013.2257973.

[4] K. Abed, "Techniques De Commande Avancees Appliquees Aux Machines De Type Asynchrone," University Mentouri of Constantine, 2010.

[5] M. A. Fnaiech, F. Betin, G.-A. Capolino, and F. Fnaiech, "Fuzzy Logic and Sliding-Mode Controls Applied to Six-Phase Induction Machine With Open Phases," IEEE Trans. Ind. Electron., vol. 57, no. 1, pp. 354-364, Jan. 2010, doi: 10.1109/TIE.2009.2034285.

[6] Liangyong Wang, Tianyou Chai, and Lianfei Zhai, "Neural-Network-Based Terminal Sliding-Mode Control of Robotic Manipulators Including Actuator Dynamics," IEEE Trans. Ind. Electron., vol. 56, no. 9, pp. 3296-3304, Sep. 2009, doi: 10.1109/TIE.2008.2011350.

[7] C. Ed-dahmani, H. Mahmoudi, M. El Azzaoui, and B. Anass, "FPGA Based Variable Structure Control of Direct Drive Permanent Magnet Synchronous Generator Wind Power," SSRN Electron. J., 2018, doi: 10.2139/ssrn.3185348.

[8] M. A. Fnaiech, F. Betin, and G. A. Capolino, "Sliding mode control applied to the inner loop regulation of a faulted six-phase induction machine (6PIM)," in 2009 IEEE International Electric Machines and Drives Conference, 2009, pp. 1305-1310, doi: 10.1109/IEMDC.2009.5075372.

[9] C.-K. Lin, "Nonsingular Terminal Sliding Mode Control of Robot Manipulators Using Fuzzy Wavelet Networks," IEEE Trans. Fuzzy Syst., vol. 14, no. 6, pp. 849-859, Dec. 2006, doi: 10.1109/TFUZZ.2006.879982.

[10] Shaocheng Tong and Han-Xiong Li, "Fuzzy adaptive sliding-mode control for mimo nonlinear systems," IEEE Trans. Fuzzy Syst., vol. 11, no. 3, pp. 354-360, Jun. 2003, doi: 10.1109/TFUZZ.2003.812694.

[11] F.-J. Lin, J.-C. Hwang, P.-H. Chou, and Y.-C. Hung, "FPGA-Based Intelligent-Complementary SlidingMode Control for PMLSM Servo-Drive System," IEEE Trans. Power Electron., vol. 25, no. 10, pp. 2573-2587, Oct. 2010, doi: 10.1109/TPEL.2010.2050907.

[12] Wei-Te Su and Chang-Ming Liaw, "Adaptive 
positioning control for a LPMSM drive based on adapted inverse model and robust disturbance observer," IEEE Trans. Power Electron., vol. 21, no. 2, pp. 505-517, Mar. 2006, doi: 10.1109/TPEL.2005.869729.

[13] Weibing Gao and J. C. Hung, "Variable structure control of nonlinear systems: a new approach," IEEE Trans. Ind. Electron., vol. 40, no. 1, pp. 45-55, 1993, doi: 10.1109/41.184820.

[14] Z. Xiaoguang, Z. Ke, and S. Li, "A PMSM sliding mode control system based on a novel reaching law," in 2011 International Conference on Electrical Machines and Systems, 2011, pp. 1-5, doi: 10.1109/ICEMS.2011.6073586.

[15] J. Y.-C. Chiu, K. K.-S. Leung, and H. S.-H. Chung, "High-Order Switching Surface in Boundary Control of Inverters," IEEE Trans. Power Electron., vol. 22, no. 5, pp. 1753-1765, Sep. 2007, doi: 10.1109/TPEL.2007.904209.

[16] Z. Ke, Z. Xiao-guang, S. Li, and C. Chang, "Sliding mode control of high-speed PMSM based on precision linearization control," in 2011 International Conference on Electrical Machines and Systems, 2011, pp. 1-4, doi: 10.1109/ICEMS.2011.6073587.

[17] M. Karabacak and H. I. Eskikurt, "Design, modelling and simulation of a new nonlinear and full adaptive backstepping speed tracking controller for uncertain PMSM," Appl. Math. Model., vol. 36, no. 11, pp. 5199-5213, Nov. 2012, doi: 10.1016/J.APM.2011.12.048.

[18] J. Yu, B. Chen, H. Yu, and J. Gao, "Adaptive fuzzy tracking control for the chaotic permanent magnet synchronous motor drive system via backstepping," Nonlinear Anal. Real World Appl., vol. 12, no. 1, pp. 671-681, Feb. 2011, doi: 10.1016/J.NONRWA.2010.07.009.

[19] H. Bouzeria, C. Fetha, T. Bahi, I. Abadlia, Z. Layate, and S. Lekhchine, "Fuzzy Logic Space Vector Direct Torque Control of PMSM for Photovoltaic Water Pumping System," Energy Procedia, vol. 74, pp. 760771, Aug. 2015, doi: 10.1016/J.EGYPRO.2015.07.812.

[20] B. Adhavan, A. Kuppuswamy, G. Jayabaskaran, and V. Jagannathan, "Field oriented control of Permanent Magnet Synchronous Motor (PMSM) using fuzzy logic controller," in 2011 IEEE Recent Advances in Intelligent Computational Systems, 2011, pp. 587-592, doi: 10.1109/RAICS.2011.6069379.

[21] S. Dandan, D. Yugang, and Z. Chengning, "Sliding Mode Controller for Permanent Magnetic Synchronous Motors," Energy Procedia, vol. 105, pp. 2641-2646, May 2017, doi: 10.1016/J.EGYPRO.2017.03.765. 